$\xi=1$ 国

\title{
Assessing quality of web sites based on multimedia content
}

\author{
Naga Prudhvi Kolla ${ }^{1 *}$, Dr. JKR Sastry ${ }^{1}$, Dr. V Chandra Prakash ${ }^{1}$, Siva Krishna Onteru ${ }^{1}$, \\ Yeshwanth Surya Pinninti ${ }^{1}$ \\ ${ }^{I}$ Department of computer Science and Engineering, KLEF Deemed to be University, Vaddeswaram, Guntur AP \\ *Corresponding author E-mail: nagaprudhvikolla1997@gmail.com
}

\begin{abstract}
Information is being presented these days in terms of text, data, images, video, and audio. Graphics and animations. Information is being disseminated through web sites which are either dynamic or static. Quality of the WEB site is however a big question. Users are quite concerned about quality of the WEB site. Too many operations if need to be undertaken for want of quality visualisation of the content such as Images, then the users loose interest in looking at that kind of content. WEB sites are presenting the content by integrating text and data with multimedia objects. Quality visualisation of the multimedia content would be the real issue as presenting these elements. The number of operations that the user is expected to carry must be minimised as much as possible.

Quality presentation of the multimedia objects is most important for making available web sites to the customer satis-faction. Assessment of quality of the multimedia objects is needed to project the extent to which the users will be satis-fied with a web site that hosts different types of multimedia objects. In this paper the methods that computes quality of multimedia objects individually and also considering all types of multi-media objects as a whole are presented.
\end{abstract}

Keywords: Quality of WEB Sites; Quality Assessment Framework; Quality of Multimedia Objects; Quality Assessment of Multimedia Objects.

\section{Introduction}

The information exchange is predominantly taking place due to advent of Internet and WEB technologies. Most of the content these days is hosted on the WEB making it easy for the people have the access to the information in least time and negligible cost. The information hosted on the WEB is of different forms which include text, images, audio and videos. Information is also being available in streamed mode. The Web sites are being used for doing e-commerce including marketing. The way the people live is changing drastically with the content being available on the web changing. How the quality of the content hosted on the WEB needs to be assessed before taking the content hosted on web for granted. The attitude of the people requiring the information is changing heavily. The customers won't be satisfied if the WEB site is not of quality. The WEB site loses its existence and never be surfed if the quality of information hosted on the WEB is erroneous and some time has no relevance or connectedness. The quality of a website can be assessed using some quality factors such as Usability, content Reliability, Flexibility, Functionality, Portability, Maintainability, Privacy, Security, Adequacy of Information, Safety, Content, Navigation and etc. The quality of website can be assessed in many ways. The assessment can also be done using evaluation tools. Many organizations are developing their information in terms of Videos, audios, graphics, text, tables, forms, animations, Logos, dynamic content, mouse over effects, graphics etc. While some web sites are static in nature some other sites are dynamic.

Many methods existing in literature for computing the quality of the WEB site are either subjective or objective. There us prejudice involved in the subjective assessment and there is lack of completeness in the objective assessment of quality of WEB sites. Some methods are biased due to individual preferences or some purely based statistical measurements relating down time, response time etc. The quality of a web site is based on the persons who look at the WEB sites. Programmers look at the WEB site characteristics that include security, functionality and maintainability whereas the users using the WEB site look at the quality of the WEB site in terms of usability, credibility, efficiency and credibility.

Every web site has certain number of quality characteristics. The characteristics must be evaluated to assess the quality of the WEB site and also to find the extent to which the user needs are being met. Assessing the quality of the web site is quite complicated especially when the web sites are complex. The WEB sites that are related to e-commences, museums, sites that deal with animations are actually quite complicated. Even the process that is used for evaluating the quality of a web site is more complex. Most of the quality characteristics of web sites is also are interleaved and inter connected through complex logic that relates the Quality characteristics of the web site. Some of the quality factors can only be computed subjectively and some other parameters are to be evaluated objectively and some other parameters are computed quantitatively. A composite model comprising all aspects of computation of quality is required. Connectivity between subjective, objective and quantitative is requited for the development of proper quality assessment model.

The expectations of a site must first be determined. Quality parameters that are representative of the expectations must be determined and must form into a base or a quality assessment model using which the overall quality of the web site can be assessed. The metrics that measures the quality characteristic must be determined and the quantitative technique that can be used for measuring the quality characteristic must be determined..

The quality assessment methods vary from factor to factor and the number of features that must be considered shall also vary from factor to factor. Each feature and the combined effect of all the 
features must be measured through most suitable computational methods. In this paper the features and computational methods related multimedia objects are presented.

\section{Literature survey}

Miss. Kausar Fiaz Khawaja1 et al., [1] have dealt with factors that include Usability, Privacy Security, and Adequacy of information and Appearance which can be used for evaluating the quality of a WEB site. Usability is the ease of use and learnability of a humanmade object such as a tool or device. It describes the quality of user experience across websites. Appearance means the visibility of the WEB site which includes appealing, polished and professional presentation. Adequacy of Information means Putting sufficient and useful information in the website. A method has been presented paper that helps computing the quality based on the observations made while the WEB site is in use.

Vijay kumar Mantri et al. [2], have presented that quality of a WEB site can be computed using the factors such as Usability, Safety and Flexibility. Usability of a website must be effective, efficient and satisfactory. Safety of a Website must ensure that no interaction of a user with the WEB site could be ever revealed. Flexibility is the ability to add / modify / remove functionality affecting the WEB pages without damaging the functioning of current ongoing system. The authors have used a tool called Portal Data Quality Assessment Tool (PoDQA) using a quality model called Portal Data Quality Model (SPDQM).

Several quality factors have been considered by Vassilis $\mathrm{S}$ Moustakis et al., [3] that include Structure and Design, Content, Multimedia, Navigation, Appearance, Uniqueness. Information provided to the end user through user interface is called as Content, The extent to which the web site specialized or generalized, reliability and completeness of the information etc., reflects the quality of a web site considering content as a lone parameter. Every user should have a facility to move around the WEB site. Such facility is called navigation. The ability of moving around the WEB site, easy understand the moving around the web site, and the proper functioning and availability of the links reflects the quality of the navigation built into the implementation of the WEB site. The way the content is presented, speed with which the content is browsed is related to the structure of the web site. The Look and feel and the appearance of the web site is very much dependent on use of multimedia objects along with the graphics. Every web site must be differentiate and should look unique different from others. The uniqueness of the site makes more available for the users. User can very easily distinguish the unique sites.

Andrina Graniü et al., [4] have presented the quality of a WEB site from the point of portability. Portability means the ability to move the website from one host platform to another and the platform that runs the site will work on the new host.

Tanya Singh et al. [5], have used quality factors that include Usability, Privacy and Security, Adequacy of information and Appearance. Usability is the ease of use and learnability of a humanmade object such as a tool or device. It describes the quality of user experience across websites. Privacy is all about revealing information to those users who are identified by the owner of the user. Only selected users are provided with the information of those data elements intended to be shared by the owner of the data Security is all about preserving the interaction of the user with the WEB site. Adequacy of information is related to making available complete data without any loose ends that suffice the actual requirements of the end user. Appearance of a WEB site is all about displaying the content in most understandable by using colours. Graphics, sequences etc.

Anusha et. al., [6] have considered Factors such as Portability, Reliability, Functionality, Usability, Maintainability, and Efficiency to asses quality of a WEB site. Portability means the ability to move the website from one host to another and the platform that runs the site will work on the new host. Reliability means that a WEB site shall reflect the same information any number of times it is sought in the same context. It is the probability that the intended page will be available and presented to the user. Website must be Free from errors. Functionality of a website includes accuracy, security, suitability and etc. Usability is the ease of use and learnability of a human-made object such as a tool or device Maintainability includes analysability, changeability, stability, Testability. Maintainability implies the simplicity with which changes can be made to the WEB site while the WEB site is up and being used for other. Analysability includes the readability of the content and the ability to intemperate the same including the tracing of navigational paths. Stability is a feature that dictates that the same content is displayed any number of times a user visits a WEB page in the same context. Testability of a WEB site includes all those features using which the proper working of the WEB site is tested while the WEB site is up and running.

Filippo Ricca et al., [7] have considered Content, Design, Organization and user friendliness as the quality factors that must be considered in evaluating the quality of a WEB site. Organization of a Web site includes the identification of WEB pages and the way the WEB pages are linked hierarchically. The linking of the WEB pages is done in such way that is easy to navigate. The WEB pages must be simple and user friendly in the sense, the content shall be presented to the user as per preferences of the user.

Saleh Alwahaishi et. al., [8] have considered playfulness, and Level of representation of the content as the most important factors that should be considered for evaluating the Quality of a WEB site. Most of the presentation on the basement of quality framework has neither provided a framework or appropriate computational methods using which quality of a WEB site can be computed.

Layla Hasan and Emad Abuelrub [9] have proposed a general criterion for evaluating the quality of any website regardless of the type of service that it offers. The have contended that the dimensions of quality criteria that include content, design, organization and user-friendliness. These dimensions together with their comprehensive indicators and checklist can be used by web designers and developers to create quality websites to improve the electronic service and then the image of any organization on the Internet.

Kavindra Kumar Singh et al., [10] have expressed that the rapid growth of web applications increases the need to evaluate web applications quantitatively. WebQEM (Web Quality Evaluation Method) have been used for objectively trying to evaluate the web applications. Weighing a web attribute has been proved to be subjective and mostly dependent on judgements made by the experts. The authors have presented quantitative evaluation strategy to access the quality of WEB sites and Applications. The methodology proposed by them is useful to systematically assess characteristics, sub-characteristics and attributes that influence product quality. They have presented models, methods, procedures, principles and for assessing quality of a WEB site.

Long-Sheng Chen et al., [11] have presented that heavy interaction is taking place among the members especially through social WEB sites. It has become very important to consider the quality of WEB sites. The authors have attempted to define the quality factors of virtual communities and then proceeded to identify key factors by attracting new members by using feature selection technique

Naw Lay Wah et al., [12] have presented that the WEB sites must be evaluated and measured for quality. He has presented several metrics that are quite related to usability associated with good design elements such as word count, total pages, size in bytes, body text percentage, average link text count and others. He has presented the computation of WEB site quality on basis of 16 factors. He has used support vectors to predict good and bad web pages. A quantitative analysis of WEB page attributes has been presented. 


\section{Assessing quality of a web site based on multimedia objects}

The objects of type Images, Videos, Audios, Graphics and Animations are called as multimedia objects which are mixed with text and data to deliver contents to the users. The value of the content immensely increases with the use of Multimedia objects. The quality of the WEB sites is dependent on the quality of the Multimedia objects that are rendered on the WEB site. The resources files scanned and all the location of the Multimedia objects can be determined and the location references cane be stored in 5 different vectors (Image[m], Video[n], Audio[o], Graphics[p], Animations[q]) and then each of the object is scanned and the quality of the multimedia objects are assessed and then the overall quality of the WEB site considering all the objects hosted on the WEB site is computed.

Assessing Quality of the Images

The quality of an Image is based on the resolution, format, intensity, size, and brightness,. All these values of an image can be determined by accessing the properties of the Image and the values used in developing the images.

The total quality of all the images taken together $=$

\section{QIMAGES $=\sum_{1}^{\mathrm{n}}$ Qimages $[\mathrm{i}]$}

Where $\mathrm{n}=$ total number of images and Qvideo $[\mathrm{i}]=$ quality of $\mathrm{i}^{\text {th }}$ video

Quality of each image is computed considering features that includes resolution, format, intensity, size, and brightness

The following Table shows the evaluation of the quality of image objects considering different properties.

Table 1: Assessing Resolution of Images

\begin{tabular}{llllll}
\multicolumn{7}{c}{ Table 1: Assessing Resolution of Images } \\
\hline \multirow{2}{*}{ Resolution } & \multirow{2}{*}{ Measurement } & $600 \mathrm{X}$ & $800 \mathrm{X}$ & $1100 \mathrm{X}$ & $1100 \mathrm{X}$ \\
& 600 & 600 & 800 & 1100 \\
\hline & Quality Value & 0,25 & 0.50 & 0.75 & 1.00 \\
\hline
\end{tabular}

The Quality considering the resolution of all the images $=$

QIMAGESR $=\sum_{1}^{\mathrm{n}} \mathrm{Qimr}[\mathrm{i}]$

Where $\mathrm{n}=$ total number of images and Qimr [i] = quality of $\mathrm{i}^{\text {th }}$ Image

Table 2: Assessing Format

\begin{tabular}{llllll}
\hline Resolution & Format & Non standard & JPEG & ZIF & BMP \\
\hline & Quality Value & 0,25 & 0.50 & 0.75 & 1.00 \\
\hline
\end{tabular}

The Quality considering the format used for all the images

QIMAGEF $=\sum_{1}^{\mathrm{n}}$ Qimf[i]

Where $\mathrm{n}=$ total number of images and Qimf $[\mathrm{i}]=$ quality of $\mathrm{i}^{\text {th }}$ Image

Table 3: Assessing Intensity

\begin{tabular}{llllll}
\hline \multirow{2}{*}{ Intensity } & $1 \%-0 \%, 90 \%-$ & $80 \%-$ & $70 \%-$ & $60 \%-$ & $20 \%-$ \\
& $100 \%$ & $90 \%$ & $80 \%$ & $70 \%$ & $50 \%$ \\
\hline & Quality Value & 0,25 & 0.50 & 0.75 & 1.00 \\
\hline
\end{tabular}

The Quality considering the intensity of all the images

QIMAGEI $=\sum_{1}^{\mathrm{n}} \mathrm{QimI}[\mathrm{i}]$

Where $\mathrm{n}=$ total number of images and Qimi[i] = quality of $\mathrm{i}^{\text {th }}$ Image

Table 4: Assessing Brightness

\begin{tabular}{llllll}
\hline \multirow{2}{*}{ Brightness } & $1 \%-10 \%, 90 \%$ & $80 \%-$ & $70 \%-$ & $60 \%-$ & $20 \%-$ \\
& $-100 \%$ & $90 \%$ & $80 \%$ & $70 \%$ & $50 \%$ \\
\hline & Quality Value & 0,25 & 0.50 & 0.75 & 1.00 \\
\hline
\end{tabular}

The Quality considering brightness of all the images QIMAGEB = $\sum_{1}^{\mathrm{n}} \mathrm{QimB}[\mathrm{i}]$

Where $n=$ total number of images and QimB[i] $=$ quality of $\mathrm{i}^{\text {th }}$ Image

Table 5: Assessing Size

\begin{tabular}{llllll}
\hline \multirow{2}{*}{ Sizes } & \multirow{2}{*}{$80 \mathrm{~K}$} & $60 \mathrm{~K}-$ & $40 \mathrm{~K}-$ & $20 \mathrm{~K}-$ & $1-$ \\
& & $80 \mathrm{~K}$ & $60 \mathrm{~K}$ & $40 \mathrm{~K}$ & $20 \mathrm{~K}$ \\
\hline & & & & &
\end{tabular}

The Quality considering sizes of all the images

QIMAGES $=\sum_{1}^{\mathrm{n}} \mathrm{QimS}[\mathrm{i}]$

Where $\mathrm{n}=$ total number of images and QimS [i] = quality of $\mathrm{i}^{\text {th }}$ Image

Total Image quality TIMAGEQ = QIMAGESR + QIMAGEF + QIMAGEI + QIMAGEB+ QIMAGES

Assessing Quality of the Videos

Videos are occasionally launched on to the WEB site. The quality on video is dependent on number frames asserted per minute and the resolution used for displaying the video. The number of colors and the size of the Video are other factors that affect the quality of the Videos.

The quality of the videos hosted on the WEB is computed considering all the videos and the features with which a video is displayed. Following tables and expressions can be used to compute the quality of videos

The total quality of all the videos taken together

$=\mathrm{QVIDEOS}=\sum_{1}^{\mathrm{n}}$ Qvideo $[\mathrm{i}]$

Where $\mathrm{n}=$ total number of Videos and Qvideo [i] = quality of $\mathrm{i}^{\text {th }}$ video

Quality of each video is computed considering features that includes frames, resolution, colors, and size

Table 6: Number of Frames Asserted Per Minute

\begin{tabular}{llllll}
$\begin{array}{l}\text { Number } \\
\text { of frames } \\
\text { per mi- } \\
\text { nute }\end{array}$ & $\begin{array}{l}\text { Number } \\
\text { of } \\
\text { frames } \\
20\end{array}$ & $\begin{array}{l}\text { Number } \\
\text { of frames }\end{array}$ & $\begin{array}{l}\text { Number } \\
\text { of frames } \\
30-40\end{array}$ & $\begin{array}{l}\text { Number } \\
\text { of frames } \\
40-50\end{array}$ & $\begin{array}{l}\text { Number } \\
\text { of frames } \\
>50\end{array}$ \\
\hline & $\begin{array}{l}\text { Quality } \\
\text { Value }\end{array}$ & 0.25 & 0.50 & 0.75 & 1.00 \\
\hline
\end{tabular}

The Quality considering all videos considering the number Frames

QVIDEOSF $=\sum_{1}^{\mathrm{n}} \mathrm{Qvds}[\mathrm{i}]$

Table 7: Assessing Resolution of Videos

\begin{tabular}{|c|c|c|c|c|c|}
\hline Resolution & Measurement & $\begin{array}{l}600 X \\
600\end{array}$ & $\begin{array}{l}800 X \\
600\end{array}$ & $\begin{array}{l}1100 \mathrm{X} \\
800\end{array}$ & $\begin{array}{l}1100 \mathrm{X} \\
1100\end{array}$ \\
\hline & Quality Value & 0,25 & 0.50 & 0.75 & 1.00 \\
\hline
\end{tabular}

The Quality considering the resolution of all the videos

$=\mathrm{QVIDEOSR}=\sum_{1}^{\mathrm{n}} \mathrm{Qvdr}[\mathrm{i}]$

Where $n=$ total number of videos and Qvdr[i] = quality of $i^{\text {th }}$ video

Table 8: Assessing Size

\begin{tabular}{|c|c|c|c|c|c|c|}
\hline Sizes & $>$ & $80 \mathrm{~K}$ & $\begin{array}{l}60 \mathrm{~K}- \\
80 \mathrm{~K}\end{array}$ & $\begin{array}{l}40 \mathrm{~K}- \\
60 \mathrm{~K}\end{array}$ & $\begin{array}{l}20 \mathrm{~K}- \\
40 \mathrm{~K}\end{array}$ & $\begin{array}{l}1- \\
20 \mathrm{~K}\end{array}$ \\
\hline & & alue & 0,25 & 0.50 & 0.75 & 1.00 \\
\hline
\end{tabular}

The Quality considering sizes of all the vodeos

QVIDEOS $=\sum_{1}^{\mathrm{n}}$ QvdrS[i]

Where $\mathrm{n}=$ total number of videos and QvdrS [i] = quality of $\mathrm{i}^{\text {th }}$ Video 
Table 9: Assessing Colors

\begin{tabular}{llllll}
\multicolumn{7}{c}{ Table 9: Assessing Colors } \\
\hline Colors & $<40 \mathrm{~K}$ & $40 \mathrm{~K}$ & $60 \mathrm{~K}$ & $80 \mathrm{~K}$ & 1 Million \\
\hline $\begin{array}{l}\text { Quality } \\
\text { Value }\end{array}$ & 0,25 & 0.50 & 0.75 & 1.00 \\
\hline
\end{tabular}

The Quality considering colors of all the videos

$\mathrm{QVIDEOC}=\sum_{1}^{\mathrm{n}} \mathrm{QvdrC}[\mathrm{i}]$

Where $\mathrm{n}=$ total number of videos and QvdrC $[\mathrm{i}]=$ quality of $\mathrm{i}^{\text {th }}$ Video

Total Quality considering all the videos is computed as

\section{TVIDEOSQ = QVIDEOSF + QVIDEOSR + QVIDEOS + QVIDEOC}

Assessing the audio files

Audios are occasionally launched on to the WEB site. The quality on audio is dependent on number of waves used, duration of the waves and the frequency used for the waves. The echo of the sound used is also one of the quality parameters that must be used. The quality of the audios hosted on the WEB is computed considering all the audios and the features with which a audios are played. Following tables and expressions can be used to compute the quality of Audios

The total quality of all the videos taken together $=$

\section{QAUDIOS $=\sum_{1}^{\mathrm{n}}$ QAudio[i]}

Where $n=$ total number of Audios and Qaudio [i] = quality of $i^{\text {th }}$ audio

Quality of each audio is computed considering features that includes number of waves, frequency of waves, duration of the waves, and echo of the sound

Table 10: Number Waves Asserted

\begin{tabular}{llllll}
\hline $\begin{array}{l}\text { Number } \\
\text { of waves } \\
\text { per mi- } \\
\text { nute }\end{array}$ & $\begin{array}{l}\text { Number } \\
\text { of }\end{array}$ & $\begin{array}{l}\text { Number } \\
\text { of waves }\end{array}$ & $\begin{array}{l}\text { Number } \\
\text { of waves } \\
20\end{array}$ & $\begin{array}{l}\text { Number } \\
\text { of waves } \\
40-50\end{array}$ & $\begin{array}{l}\text { Number } \\
\text { of waves } \\
>50\end{array}$ \\
\hline & $\begin{array}{l}\text { Quality } \\
\text { Value }\end{array}$ & 0.25 & 0.50 & 0.75 & 1.00 \\
\hline
\end{tabular}

The Quality considering all audios considering the number of waves

$$
\text { QAUDIOW }=\sum_{1}^{\mathrm{n}} \text { Qaudw }[\mathrm{i}]
$$

Table 11: Assessing Frequency of Waves

\begin{tabular}{llllll}
\hline Waves & Measurement & $6 \mathrm{hz}$ & $8 \mathrm{hz}$ & $10 \mathrm{hz}$ & $12 \mathrm{hz}$ \\
\hline & Quality Value & 0.25 & 0.50 & 0.75 & 1.00 \\
\hline
\end{tabular}

The Quality considering the frequency of all audios =

QAUDIOF $=\sum_{1}^{\mathrm{n}}$ Qaudf[i]

Where $n=$ total number of videos and Qaudf[i] = quality of $i^{\text {th }}$ Audio

Table 12: Assessing Duration

\begin{tabular}{cllllll}
\hline \multicolumn{7}{c}{ Table 12: Assessing Duration } \\
\hline Sizes & \multicolumn{1}{c}{6 Secs } & 5 Secs & 4 Secs & 3 Secs & 2 Secs \\
\hline & Quality Value & 0,25 & 0.50 & 0.75 & 1.00 \\
\hline
\end{tabular}

The Quality considering duration of all the audios

$\mathrm{QAUDIOD}=\sum_{1}^{\mathrm{n}}$ Qaudd[i]

Where $\mathrm{n}=$ total number of audio and Qaudd [i] = quality of $\mathrm{i}^{\text {th }}$ Audio
Table 13: Assessing Echo

\begin{tabular}{llllll}
\hline Colors & $<16 \mathrm{db}$ & $16 \mathrm{db}$ & $14 \mathrm{db}$ & $12 \mathrm{db}$ & $10 \mathrm{db}$ \\
\hline & Quality Value & 0,25 & 0.50 & 0.75 & 1.00 \\
\hline
\end{tabular}

The Quality considering echo of all the audios

$\mathrm{QAUDIOE}=\sum_{1}^{\mathrm{n}}$ Qaude $[\mathrm{i}]$

Where $n=$ total number of videos and Qaude [i] = quality of $\mathrm{i}^{\text {th }}$ Audio

Total Quality considering all the audio is computed as

TAUDIOQ = QAUDIOW + QAUDIOF + QAUDIOD +
QAUDIOE

Graphics are helpful for showing the trends, performance analysis and dependencies between business parameters. Graphics are represented as images and therefore the quality computations of the same can be undertaken as in the cases of the images. Some web sites generate the graphs dynamically as graphics tools and the graphs are displayed in the display area. Computation of quality of the graphs in such case is complicated; the quality assessment of a Graph is dependent on the type of graphs and type of data used for displaying the Graph. The following Table provides a basis for computation of quality of the Graphs. The fetters

Table 14: Assessing Graphics

\begin{tabular}{|c|c|c|c|c|c|c|}
\hline $\begin{array}{l}\text { Type } \\
\text { of } \\
\text { Graph }\end{array}$ & $\begin{array}{l}\text { Type of } \\
\text { data }\end{array}$ & $\begin{array}{l}\text { Features } \\
\text { X Coor- } \\
\text { dinate }\end{array}$ & $\begin{array}{l}\text { Y Coor- } \\
\text { dinate }\end{array}$ & $\begin{array}{l}\text { Num- } \\
\text { ber of } \\
\text { Bars }\end{array}$ & $\begin{array}{l}\text { Bar } \\
\text { widt } \\
\text { h }\end{array}$ & $\begin{array}{l}\text { Radi- } \\
\text { us }\end{array}$ \\
\hline $\begin{array}{l}\text { XY } \\
\text { plot }\end{array}$ & $\begin{array}{l}\text { Continu- } \\
\text { ous }\end{array}$ & $\sqrt{ }$ & $\sqrt{ }$ & - & - & - \\
\hline $\begin{array}{l}\text { Scatter } \\
\text { Dia- } \\
\text { gram }\end{array}$ & Discrete & $\sqrt{ }$ & $\sqrt{ }$ & & & \\
\hline $\begin{array}{l}\text { Pie } \\
\text { Dia- } \\
\text { gram }\end{array}$ & Percentile & $\sqrt{ }$ & - & - & - & $\sqrt{ }$ \\
\hline $\begin{array}{l}\text { Bar } \\
\text { Dia- } \\
\text { gram }\end{array}$ & $\begin{array}{l}\text { Continu- } \\
\text { ous }\end{array}$ & $\sqrt{ }$ & $\sqrt{ }$ & & & $\sqrt{ }$ \\
\hline
\end{tabular}

The resources files are scanned to determine the number of graphics files, the type of data used for generating the graphics and the features used for in respect of each of the Graph. The details collected for each of the Graph are compared with the entries above mentioned table and the quality is assessed as $100 \%$ if everything tallies or otherwise quality is computed as zero $\%$ of Graphs with salient features =

Total Graphs with all the features $/$ Total Graphs featured in the web site

Table 15: The Quality of the Graphs Is Computed As Per the Table Below

\begin{tabular}{|c|c|c|c|c|}
\hline $\begin{array}{l}\% \text { of } \\
\text { graphs } \\
\text { with salient } \\
\text { features }\end{array}$ & $\begin{array}{l}\% \text { of graphs } \\
\text { with salient } \\
\text { features = } \\
40\end{array}$ & $\begin{array}{l}\% \text { of graphs } \\
\text { with salient } \\
\text { features = } \\
60\end{array}$ & $\begin{array}{l}\% \text { of graphs } \\
\text { with salient } \\
\text { features = } \\
80\end{array}$ & $\begin{array}{l}\% \text { of graphs } \\
\text { with salient } \\
\text { features = } \\
100\end{array}$ \\
\hline $\begin{array}{l}\text { Quality } \\
\text { Value }\end{array}$ & 0.25 & 0.50 & 0.75 & 1.00 \\
\hline
\end{tabular}

Total quality of the Graphics is represented by

TGRAPHICSQ $=\sum_{1}^{\mathrm{n}}$ Graphicsqi

Where $\mathrm{n}=$ featured Graphics

Assessing Quality of Animations

Animations are rarely used for displaying meaning of web contents. Animations are used for showing some special effects of an occurrence. The quality of animation can be assessed in terms of 
frames used, duration of the animation and the rate of streaming of the animations.

The quality of the animations hosted on the WEB is computed considering all the animations and the features with which an animation is displayed. Following tables and expressions can be used to compute the quality of videos

The total quality of all the videos taken together

\section{$=$ QANIMATIONS $=\sum_{1}^{\mathrm{n}}$ Qanimations $[\mathrm{i}]$}

Where $\mathrm{n}=$ total number of Animations and Qanimation [i] = quality of $i^{\text {th }}$ Animation

Quality of each animation is computed considering features that includes frames, duration and rate of animation.

Table 16: Number of Frames Used

\begin{tabular}{llllll}
\hline $\begin{array}{l}\text { Number } \\
\text { of } \\
\text { frames }\end{array}$ & $\begin{array}{l}\text { Number } \\
\text { of } \\
\text { frames },\end{array}$ & $\begin{array}{l}\text { Number } \\
\text { of frames } \\
20-30\end{array}$ & $\begin{array}{l}\text { Number } \\
\text { of frames } \\
30-40\end{array}$ & $\begin{array}{l}\text { Number } \\
\text { of frames } \\
40-50\end{array}$ & $\begin{array}{l}\text { Number } \\
\text { of frames } \\
>50\end{array}$ \\
\hline & $\begin{array}{l}\text { Quality } \\
\text { Value }\end{array}$ & 0.25 & 0.50 & 0.75 & 1.00 \\
\hline
\end{tabular}

The Quality considering all animations considering the number Frames

QANIMATIONSF $=\sum_{1}^{\mathrm{n}}$ Qanif[i]

Table 17: Assessing Duration of Animations

\begin{tabular}{llllll}
\hline \multirow{2}{*}{ Resolution } & \multirow{2}{*}{ Measurement } & $\begin{array}{l}6 \text { secs and } \\
\text { above }\end{array}$ & $\begin{array}{l}5 \\
\text { secs }\end{array}$ & $\begin{array}{l}4 \\
\text { secs }\end{array}$ & 3 secs \\
\hline & Quality Value & 0,25 & 0.50 & 0.75 & 1.00 \\
\hline
\end{tabular}

The Quality considering the duration of the Animations

$=\mathrm{QANID}=\sum_{1}^{\mathrm{n}}$ Qanid $[\mathrm{i}]$

Where $\mathrm{n}=$ total number of videos and Qanid[i] $=$ quality of $\mathrm{i}^{\text {th }}$ animation

Table 18: Assessing Animation Rate

\begin{tabular}{lllll}
\hline $\begin{array}{l}\text { Animation } \\
\text { rate }\end{array}$ & $\begin{array}{l}\text { 4 Frames / } \\
\text { sec }\end{array}$ & $\begin{array}{l}\text { 6 Frames / } \\
\mathrm{sec}\end{array}$ & $\begin{array}{l}\text { 8Frames / } \\
\mathrm{sec}\end{array}$ & $\begin{array}{l}10 \text { Frames / } \\
\mathrm{sec}\end{array}$ \\
\hline $\begin{array}{l}\text { Quality } \\
\text { Value }\end{array}$ & 0,25 & 0.50 & 0.75 & 1.00 \\
\hline
\end{tabular}

The Quality considering sizes of all the Animations

QANIRATE $=\sum_{1}^{\mathrm{n}}$ QaniR[i]

Where $\mathrm{n}=$ total number of videos and QaniR [i] = quality of $\mathrm{i}^{\text {th }}$ Animations

Total Quality considering all the Animations is computed as

TANIMATIONQ = QANIF + QANID + QANIRATE

Total quality of the entire Multimedia hosted on the WEB is represented as

\section{TMULTIMEDIA = TIMAGESQ $*$ TVIDEOSQ $*$ TAUDIOQ * TGRAPHICSQ * TANIMATIONSQ}

\section{Conclusions}

Every web site must be meticulously designed and developed for the use of information hosted on the WEB site. Most of the world is dependent on the quality of information hosted on the WEB site. The dependability on a web site for information can be expressed in terms of the quality of the WEB site. Many factors are to be considered for computing the quality of a WEB site. Multimedia is one such factor. Every factor must be expressed using the computational expressions so that the factor is expressed in quantitative terms. Every factor may involve in subsidiary factors existing in hierarchical fashion. The computation of the quality must be expressed considering computations of the entire subsidiary factors. The computation of the quality of Multimedia hosted on of the WEB site can be expressed in terms of quality of images, videos, audios, graphics and Images. The quality of each of these objects is computed considers their related features.

\section{References}

[1] Miss. Kausar Fiaz Khawaja1, Dr. Rahat Hussain Bokhari2, Exploring the Factors Associated With Quality of Website Department of Technology Management, International Islamic University, Islamabad, Pakistan, Vol.10, Issue 14 November 2010, Pg37-45.

[2] VijaykumarMantri, Dr. S. Kalaimagal, Dr N.Srinivasu, An Introspection of Web Portals Quality Evaluation, Vol.5, No.9, DOI:10.15693/ijaist/2016.v5i9.33-38

[3] Vassilis S. Moustakis1,2, Charalambos Litos1, Andreas Dalivigas1, and Loukas Tsironis1, Website quality assessment criteria , Proceedings of the Ninth International Conference on Information Quality , 2004

[4] Andrina Graniü, Ivica Mitroviü* and Nikola Maranguniü , Usability Evaluation of Web Portals , Proceedings of the ITI 2008 30th Int Conf. on Information Technology Interfaces, June 23-26, 2008

[5] Tanya Singh, Sachin Malik,Darothi Sarkar, E-Commerce Website Quality Assessment based on Usability, Department of Computer Science \& Engineering Amity University Uttar Pradesh Noida, India Pg101-105

[6] R.Anusha, A Study on Website Quality Models, Department of Information Systems Management, M.O.P Vaishnav College For Women(Autonomous),Chennai, Volume 4, Issue 12, December 2014,Pg:1-5.

[7] Filippo Ricca and Paolo Tonella, Analysis and Testing of Web Applications, Centro per la Ricerca Scientifica e Tecnologica, I-38050 Povo (Trento), Italy,

[8] Saleh Alwahaishi1 and Václav Snášel2, Assessing the LCC Websites Quality, (C) Springer-Verlag Berlin Heidelberg 2010, F. Zavoral et al. (Eds.): NDT 2010, S I, CCIS 87,2010, pp. 556-565

[9] Layla Hasan1 and Emad Abuelrub, Assessing the Quality of Web Sites, Applied Computing and Informatics, Volume 9, Issue 1, January 2011, Pages 11-29

[10] Kavindra Kumar Singh, Dr. Praveen Kumar, Jitendra Mathur, Implementation of a Model for Websites Quality Evaluation - DU Website, International Journal of Innovations \& Advancement in Computer Science IJIACS ISSN 2347 - 8616 Volume 3, Issue 1 2014

[11] Long-Sheng Chen1, and Pao-Chung Chang, Identifying Crucial Website Quality Factors of Virtual Communities, Proceedings of the International Multi-Conference of Engineers and computer scientists, Vol 1, IMECS 2010

[12] Naw Lay Wah, An Improved Approach for Web Page Quality Assessment, IEEE Student Conference on Research and Development, 2011 . 